\title{
Development report of the next generation of civil engineering
}

\author{
Zhengwei Bai ${ }^{1}$, Eeyu $\mathrm{Zhu}^{1 *}$ \\ ${ }^{1}$ Dept. of Civil Engineering., Beijing Jiaotong University., Shangyuancun 3rd, Beijing, China, 100044 \\ Corresponding Author: Eryu Zhu, Professor of Bridge Department, Beijing Jiaotong University, Ph.D, China.
}

\begin{abstract}
The development of civil engineering technology is a major issue related to the national economy and people's livelihood, especially in the modern era where new technologies are emerging in all walks of life. Combining with the current development status of civil engineering technology in the world today, the author combed the new technologies closely related to the development of civil engineering technology in recent years. These new technologies mainly include: assembly structure, intelligent manufacturing, 3D printing, and industrial digitization. The existing high-tech and civil engineering technology developments are combined. Based on the current domestic and foreign technological development environment, the author puts forward the development forecast of the next generation of civil engineering technology and the company's countermeasures. These predictions and suggestions are of great significance for the national government to formulate policies or the guidance of modern enterprises to formulate development strategies.
\end{abstract}

\section{Introduction}

Civil engineering is an important part of national construction and development, and it involves many aspects such as bridges and highways. It can be said that the development speed and degree of a country are closely related to the development status of civil engineering in that country. After the founding of New China, through continuous exploration and reforms, the socio-economic level has been continuously improved, and the level of cultural and scientific information technology applications has also been continuously improved. For the civil engineering industry, its construction mode presents a new development trend.

Regarding the understanding of the future development direction of the next generation of civil engineering, Sun, J[1] pointed out that as most countries in the world attach importance to Industry 4.0, intelligent manufacturing methods based on intelligent equipment production will be the general trend of the future development of the world's industrial system. Industrial digitization is also one of the hottest issues discussed by engineers and civil engineering experts in the industry in recent years. Chen, $\mathrm{KH}[2]$ pointed out that with the advent of the post-epidemic era, the original informatization development model will be banned by digitalization represented by XR (Extended Reality), digital twins, and real-time design. Xie, JK[3] and others studied the development of prefabricated structures in civil engineering, and pointed out that prefabricated structures are conducive to the promotion of intelligent manufacturing and the digital development of the entire life cycle of buildings. Shrive, NG[4] pointed out that with the continuous development of science and technology in recent years, the construction of factories has a trend towards IoT(Internet of Things), service network, data network, inter-factory Internet, and equipment integration.

The author mainly summarizes and analyzes the influence of the development trend of the industry from the current development of civil engineering, the application of fabricated structures, the application of intelligent manufacturing, the application of 3D printing technology and the development trend of digitalization.

\section{The development trend of the next generation of civil engineering}

\subsection{Current status of domestic civil engineering development}

(1) Wide application of prestress technology

In civil engineering structures, the application of prestressing technology can greatly improve the performance and strength of the structure. For this reason, researchers have been continuously applying and developing new materials that can meet the requirements of engineering structures in the process of engineering construction. Researchers found that the full application of prestressing technology to concrete structures can greatly improve the anti-riot, fire and seismic performance of concrete structures. At the same time, the durability of the structure is also increased. The continuous improvement of prestressing technology has promoted the application of this technology in all aspects of civil engineering, including high-rise buildings, load-bearing projects and large-span structures.

\footnotetext{
*eyzhu@bjtu.edu.cn
} 
(2) Building materials are constantly updated and upgraded

With the continuous expansion of the construction scale of civil engineering structures and the continuous development of high-strength prestressed steel technology, engineers have found that the strength of building materials directly limits the ultra-high strength of highstrength prestressed steel. At the same time, a series of research results have been achieved in the area of highstrength concrete materials based on the new UHPC. But with the development of science and technology, these materials also need to be constantly updated and upgraded. The materials are mainly developing in the direction of green environmental protection, high strength and durability, and high efficiency and economy. The scale of the global new materials market from 2016 to 2020 is shown in Figure 1.

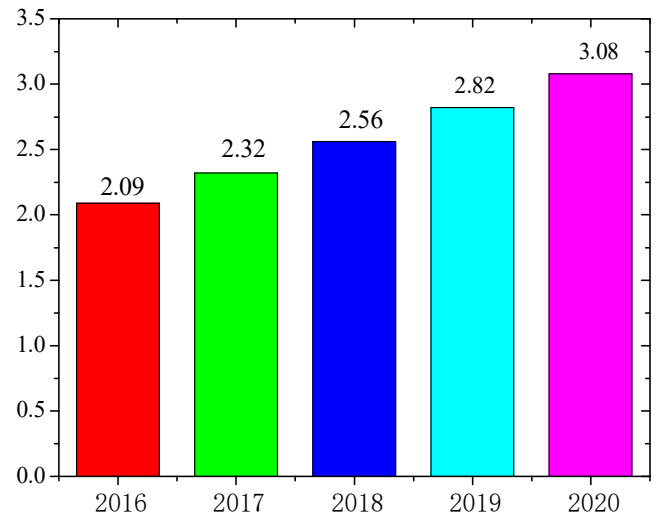

Figure 1. The scale of the global new materials market from 2016 to 2020 (US\$100 million)

(3) Development and construction of underground space

According to the statistical data of iResearch Consulting, there are now more than 20 cities in our country that have developed and constructed underground spaces. The construction and implementation of subway projects have made outstanding contributions to the construction of underground space. As of mid-2020, our country has developed a number of light rail and subway projects under construction and completion, with a total length of 32 kilometers. In this regard, it can be said that light rail and subway projects are an important manifestation of our country's development and construction of underground space, and a sign of progress in civil engineering projects.

(4) The structural design of civil engineering is improving day by day

Structural design is the most important factor affecting structural quality. Basically, in order to ensure the overall quality of the building, it is very important to improve the design of the structure. Due to the rapid development of social economy and the continuous advancement of science and technology, seismic loads and wind loads are widely used as consideration factors in the design of civil engineering buildings. Due to the current situation, our country's building structure is developing towards superhigh height and super-flexibility.

\subsection{Development characteristics of civil engineering in our country}

The development of our country's civil engineering industry has made great progress in recent years. Although it started late, it has led the world on some basis. Generally speaking, it has the following characteristics:

- High-rise buildings are not only built more and more, but also built higher. Structural systems and layouts are also becoming increasingly diversified.

- The highway and railway transportation business are advancing by leaps and bounds, and the mileage of high-grade highways is increasing rapidly.

- At present, the number of urban buildings in my country, especially houses, cannot meet people's needs.

- Although the development of civil engineering construction sites is relatively fast, it still cannot meet people's needs.

\subsection{Development trends of civil engineering at home and abroad}

(1) Urban construction will extend to high and deep aspects

The socio-economic level has improved steadily. The number of large cities and megacities is growing rapidly. People's demand for housing is also growing. An inch of land and an inch of gold have become a common consciousness among urban residents.

(2) Rail transit will gradually expand underground

The maturity of material conditions provides an opportunity for the development of our country's underground space. From the perspective of the development and use of underground space, the main controlling factor is cost. Therefore, to reduce the total cost of constructing underground spaces, new technologies must be developed.

(3) The port and waterway engineering project will open up to the ocean and desert

Making full use of marine resources in accordance with technical conditions is an innovative task that mankind continues to expand. The ocean is more complicated than the land, but the huge potential of the ocean is a huge temptation for mankind. With the passage of time and the advancement of science and technology, people have made some amazing achievements in the field of civil engineering in the ocean.

\section{Application of fabricated structure}

The prefabricated structure is the abbreviation of the prefabricated concrete structure, which is a concrete structure formed by assembling and connecting prefabricated components as the main force-bearing components. Fabricated reinforced concrete structure is one of the important directions for the development of building structures in our country. It is conducive to the development of our country's construction 
industrialization and can improve production efficiency and save energy. The development of prefabricated structures is also conducive to the development of green and environmentally friendly buildings and improve the quality of construction projects.

\subsection{Development status at home and abroad}

In the early 1960s, prefabricated buildings appeared in the former Soviet Union, some countries in Eastern Europe and France, and then gradually spread to the United States, Canada, Japan and other countries. At present, the application density of assembled monolithic concrete structures in civil engineering in developed countries is: $35 \%$ in the United States, $50 \%$ in Russia, and 35\%-40\% in Europe.

In 1997, the United States Uniform Building Code allowed the use of precast concrete structures in areas with high seismic intensity. The United States has successfully applied prefabricated buildings to residential, industrial, cultural and sports buildings, such as the Phoenix Convention Center in Arizona and the JL Financial Center in Northern Lorraine.

In Europe, especially in the Nordic countries, prefabricated concrete buildings have a long history and have accumulated a lot of experience in technology. As early as the 1970 s, there were more than 450 prefabricated component manufacturers. Among them, the IMC system of the former Yugoslavia has withstood the test of strong earthquakes in the Banyalu area of Yugoslavia before 1969 and 1981, and the system has shown good seismic performance.

As early as the 1950s and 1970s, the structural system of the French housing industry had used building construction techniques based on fully assembled slabs and tool formwork. In the 1970s, there was a transition to the "second-generation construction industrialization" with the production and use of general-purpose components and equipment. In 1978, the Ministry of Housing proposed to promote the "structural system."In the 1990s, the industrialization of French architecture has developed in the direction of modernization of the housing industry. Japan's prefabricated concrete buildings continued to develop from the Second World War to 1990, and they have been widely used in high-rise and super high-rise buildings in earthquake areas. Compared with developed countries, there is a huge gap in the market share of prefabricated construction in our country.

The "Twelfth Five-Year" Green Building and Green Ecological Regional Development Plan issued by the Ministry of Housing and Urban-Rural Development in 2013 clearly stated for the first time that our country should speed up the formation of industrialized building systems such as prefabricated concrete and steel structures.

\subsection{Advantages of fabricated structure}

Table1. Summary table of comparison of features between fabricated structure and cast-in-place structure.

\begin{tabular}{|c|c|c|}
\hline Content & Prefabricated concrete structure & Cast-in-place concrete structure \\
\hline Productivity & $\begin{array}{l}\text { On-site assembly, high production efficiency, } \\
\text { reducing labor costs by } 5-6 \text { days/layer, and labor } \\
\text { reduction by more than } 50 \%\end{array}$ & $\begin{array}{l}\text { There are many on-site procedures, low production } \\
\text { efficiency, large labor input, 6-7 days/layer, and low- } \\
\text { cost labor }\end{array}$ \\
\hline $\begin{array}{l}\text { Engineering } \\
\text { Quality }\end{array}$ & $\begin{array}{l}\text { The error is controlled to millimeter level, the } \\
\text { wall has no leakage, no cracks, and } 100 \% \\
\text { plaster-free works can be realized indoors }\end{array}$ & $\begin{array}{l}\text { The error is controlled at the centimeter level, the space } \\
\text { size is deformed, and the installation of parts is difficult } \\
\text { to achieve standardization, and the base quality is poor }\end{array}$ \\
\hline $\begin{array}{l}\text { Technology } \\
\text { integration }\end{array}$ & $\begin{array}{l}\text { It can realize the integration and refinement of } \\
\text { design, production and construction through } \\
\text { standardization and assembly to form integrated } \\
\text { technology }\end{array}$ & $\begin{array}{l}\text { It is difficult to realize the standardization and } \\
\text { refinement of decoration parts. It is difficult to realize } \\
\text { the integration of design and construction and } \\
\text { informatization. }\end{array}$ \\
\hline Save resources & $\begin{array}{l}\text { Construction saves } 60 \% \text { of water, } 20 \% \text { of } \\
\text { materials, } 20 \% \text { of energy, } 80 \% \text { of waste } \\
\text { reduction, and } 70 \% \text { of scaffolding and support } \\
\text { frames }\end{array}$ & $\begin{array}{l}\text { Large water consumption, high electricity consumption, } \\
\text { serious waste of materials, a lot of garbage, a lot of } \\
\text { scaffolding, support frame }\end{array}$ \\
\hline $\begin{array}{c}\text { Environmental } \\
\text { protection }\end{array}$ & $\begin{array}{l}\text { No dust, no waste water, and no noise on the } \\
\text { construction site }\end{array}$ & $\begin{array}{l}\text { Dust, waste water, garbage, and noise at the } \\
\text { construction site }\end{array}$ \\
\hline
\end{tabular}

\section{Application of intelligent manufacturing}

\subsection{What is intelligent manufacturing?}

Intelligent manufacturing is the whole process of "manufacturing" of construction projects, and it is the general term for project planning, design and construction based on the consideration of the whole life cycle. Intelligent construction is the completion of various technological operations by robots with complementary functions within a predetermined time and space. The ultimate goal is to realize a construction method that deeply integrates artificial intelligence and construction requirements.[5,6]

Promoting smart construction should focus on three key points:

- Building a management and control platform for engineering construction information model.

- Digital collaborative design.

- Robot construction. 


\subsection{Basic concepts of intelligent manufacturing}

It was first proposed by American Wright Bonn in 1988. Intelligent manufacturing in the traditional sense is limited to the production process and only involves the intelligence of individual units. Due to the limitation of the technical conditions at the time, there is no data flow. With the development of a new generation of information technology and its continuous penetration in the manufacturing sector, the biggest feature of intelligent manufacturing is data interconnection. It breaks the bottleneck that traditional intelligent manufacturing is limited to the production process, extends to the entire production process, and then integrates into the entire production activity.

Table2. Characteristics of production in the industry 4.0 era.

\begin{tabular}{|c|c|c|}
\hline & Mass production & Mass customization \\
\hline $\begin{array}{l}\text { Management } \\
\text { philosophy }\end{array}$ & $\begin{array}{l}\text { Focus on structural safety and win the market at } \\
\text { low cost }\end{array}$ & $\begin{array}{l}\text { Focus on engineering needs and quickly respond } \\
\text { to win the market }\end{array}$ \\
\hline Drive method & $\begin{array}{l}\text { Arrange production according to market } \\
\text { forecasts and structural design, which is a push- } \\
\text { type production method }\end{array}$ & $\begin{array}{l}\text { According to the needs of the project, the } \\
\text { assembly design and production are carried out, } \\
\text { which is a pull production method }\end{array}$ \\
\hline Core & High efficiency through stability and control rate & $\begin{array}{l}\text { Realize the diversity of product production } \\
\text { structure through mechanization and intelligence }\end{array}$ \\
\hline Strategy & $\begin{array}{l}\text { Cost leadership strategy: gain competitive } \\
\text { advantage by reducing costs and improving } \\
\text { production efficiency }\end{array}$ & $\begin{array}{l}\text { Differentiation strategy: gain competitive } \\
\text { advantage through quick response and } \\
\text { personalized products }\end{array}$ \\
\hline The goal & $\begin{array}{l}\text { Realize large-scale production of engineering } \\
\text { structure, reduce manpower and material } \\
\text { resources, and save resources }\end{array}$ & $\begin{array}{l}\text { Realize diversified structural production methods } \\
\text { and quickly adjust structural production }\end{array}$ \\
\hline
\end{tabular}

\subsection{Existing problems of our country's intelligent manufacturing}

(1) The foundation of intelligent manufacturing is still relatively weak;

(2) Intelligent manufacturing lacks the depth of the supply chain;

(3) The basic system of intelligent manufacturing is not yet perfect.

From a national perspective, the main significance of intelligent manufacturing includes: Conforming to the trend of the times and mastering the right to speak in international standardization; The importance of standardization; Respond to national policies and help industrial upgrading; Large-scale complex structures can be produced on a large scale.

\subsection{Application of Intelligent Manufacturing}

The characteristics of intelligent manufacturing: Enhance production flexibility; Reduce the flow of personnel and shortage of skilled workers; Reduce waste of raw materials, save resources, and protect the environment; Improve product consistency and improve product quality; Reduce costs and expand production capacity; Improve standardization and meet safety production regulations.

In the era of Industry 4.0, civil engineering production enterprises must transform and upgrade (see table 2).

\subsection{Examples of intelligent manufacturing}

(1) Production of CRTSIII type high-speed railway track slab

High-speed railway CRTS III type ballastless track prestressed concrete track slab is a high-speed railway ballastless track structure with independent intellectual property rights in our country. A new ballastless track structure has been developed based on the advantages of Japanese type I plate, German type II plate, domestic turnout plate and post-tensioned type III plate. The most mature production method for CRTS III high-speed railway track slabs is through the matrix pedestal method and the unit flow method manufacturing technology. Figure 2 shows the schematic diagram of the unit flow method, and Figure 3 shows a schematic diagram of the matrix pedestal method. 


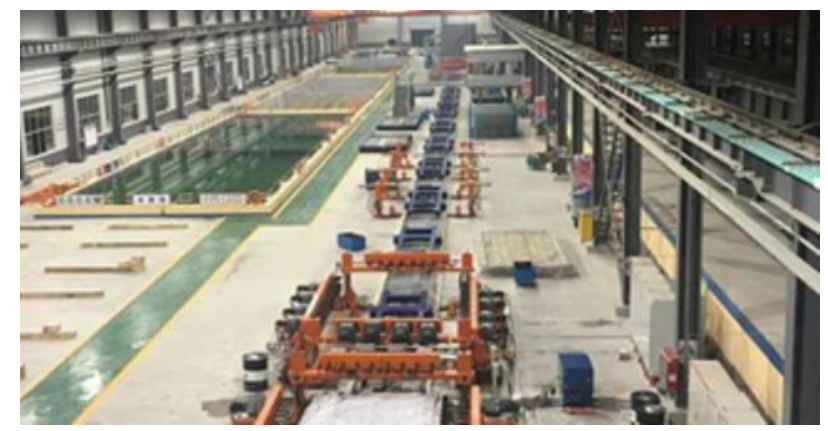

Figure 2. Unit flow method.

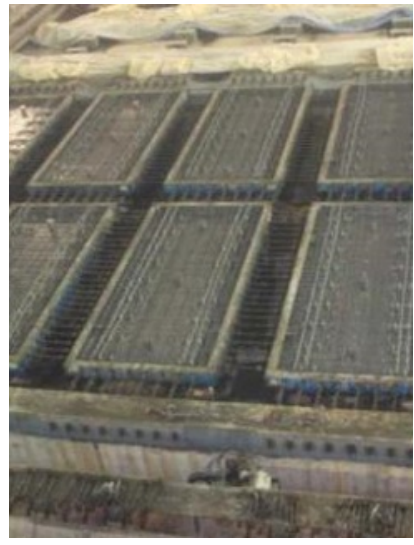

Figure 3. Matrix pedestal method.

(2) The development of intelligent manufacturing robots

With the disappearance of the demographic dividend, China's construction industry is facing tremendous pressure on labor costs, as well as a series of problems such as high risks and low production efficiency. Whether in developed countries in Europe and the United States or China in the process of adjustment and development, construction companies have been stuck in the dilemma of lack of first-line skilled workers. In the context of the transformation and upgrading of modern manufacturing and Internet service industries, the traditional construction industry has gradually lost its appeal to the younger generation.[7]

(3) The significance of introducing robots in the construction industry

- Improve production efficiency

- Guarantee the safety of personnel

- The inevitable choice of labor shortage

\section{Application of 3D printing technology}

\subsection{Basic concepts of 3D printing technology}

3D printing technology, also known as additive manufacturing technology. The typical application in the field of civil engineering is the concrete 3D printed arch bridge, as shown in Figure 5. The prefabricated concrete 3D printed Zhaozhou Bridge draws on the construction experience of the built 3D printed buildings, and introduces BIM virtual simulation technology and modern intelligent monitoring methods.[8]

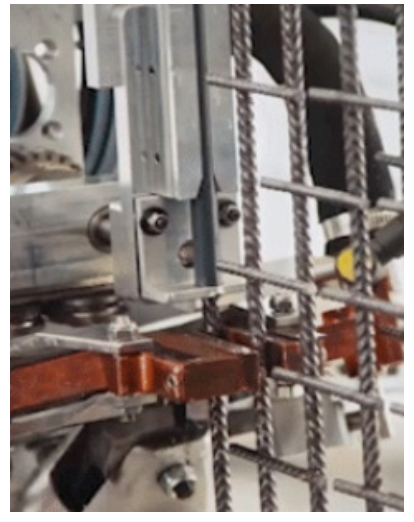

Figure 4. Rebar automatic binding robot.

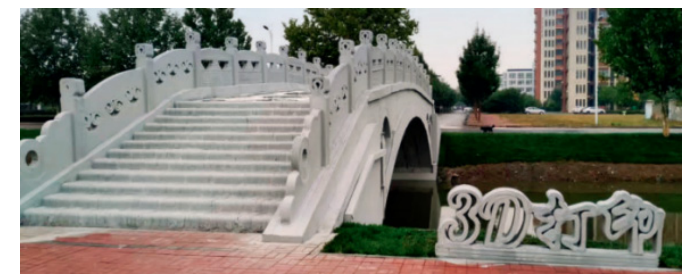

Figure 5. Concrete 3D printing Zhaozhou Bridge.

\subsection{Application of 3D printing technology}

(1) Color printing technology

Based on its unique advanced UV inkjet printing technology, Japan Mimaki launched the 3DUJ-553 fullcolor 3D printer in 2017, which is the world's first 3D printer that provides more than 10 million colors. The 3D color printing model is shown in Figure 6.

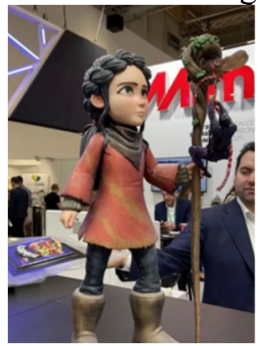

Figure 6. 3D color printing model.

(2) $3 \mathrm{D}$ printing technology in the clothing industry

3D printing technology will bring a series of innovations to the textile and apparel industry. Compared with traditional clothing production technology, 3D printing technology has the following advantages: 
- $3 \mathrm{D}$ printing technology allows the design to be produced at will, and truly achieve personalization.

- One-time molding, fast manufacturing, eliminating the need for multiple processes of traditional technology.

- 3D printing technology adopts the volume increase method instead of the traditional volume subtraction method, which saves raw materials and basically no waste is generated.

With the rapid development of 3D printing technology and the continuous research and development of new textile materials, garment processing will realize automated "single-quantity single-cutting".

\subsection{Application of 3D printing in civil engineering}

(1) The concrete book house printed by robot 3D

The design and construction of the bookstore shows that as a way of intelligent construction, 3D printing not only saves materials and manpower, but also has high construction efficiency and fast construction speed, and it can realize the construction of irregular shapes and ensure high-quality construction quality.[9]

(2) Application of 3D printing in intelligent manufacturing of assembled monorail transit

The most important component in the intelligent manufacturing of prefabricated monorail transit is the guideway, and its core technology is $3 \mathrm{D}$ printing technology. According to the three-dimensional design model of the engineering structure, this technology first automatically installs and manufactures the skeleton of the engineering structure such as steel bars, steel beams, steel tubes, etc., and then it uses a 3D printer to spray concrete layer by layer on the surface or inside of the engineering structure skeleton. The entire printing process is precisely controlled by the computer system, so as to realize the three-dimensional rapid and intelligent manufacturing of the engineering structure.

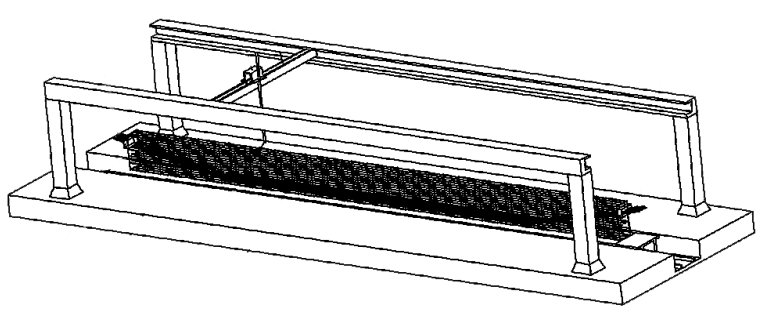

Figure 7. 3D printing technology with steel skeleton.

\section{Digitization officially enters the stage of history}

\subsection{Basic concepts of digitalization}

Informatization means using real money for data. Digitization means using data for real money. Three enabling technologies in the post-epidemic era will fully reshape the engineering construction industry: XR visual retrieval; Digital twins; Real-time design.[10]
When formulating the national economic and social development plan, the government pointed out that it is necessary to persist in innovation-driven development and comprehensively shape new development advantages. Accelerating digital development can provide continuous impetus for comprehensively shaping new development advantages. We need to rely on the innovation drive of digital technology to continuously cultivate new industries and generate new kinetic energy.

\subsection{The technological revolution brings opportunities for digital transformation}

The new round of scientific and technological revolution will provide resources and platform foundation for scientific and technological innovation. It will not only promote the rapid development of digital technology, but will also promote the development of cross-integration of digital technology and other technologies. The new round of scientific and technological revolution promotes social innovation and development, and reshapes the development momentum and governance models of education, medical care, transportation, environment, and administration.

\subsection{Digitization will reshape the innovation and development economic system}

(1) Digitization will expand capacity and optimize the innovative production factor system

(2) Digitization will promote the occurrence and development of innovation

(3) Digitization will change the way and motivation of innovation

\subsection{The internal and external environment of China's digital transformation}

(1) External environment

Major countries and organizations in the world have successively promoted digital strategies for innovation and development. They regard it as a development priority for strategic layout, and at the same time attach importance to the construction of digital infrastructure and regard it as a good software and hardware condition for digital transformation.

(2) Internal environment

- From the perspective of the demand for digital transformation from the development of technological innovation. Our country urgently needs a new scientific research paradigm to promote scientific and technological development.

- From the perspective of industrial innovation and development's demand for digital transformation. At present, our country's industrial innovation and development are facing many challenges, and digital transformation is urgently needed.

- From the perspective of social innovation and development's demand for digital transformation, the problems of fairness, efficiency, and quality 
in our country's social development can be solved through digital transformation.

\section{Conclusions and prospects}

In the contemporary era when high-tech emerges endlessly, the development of civil engineering technology is moving towards the fast lane. Its main features are: assembly of structural forms, mechanization of construction modes, intelligence of management methods, and digitization of information management. After the country put forward the national strategic plan of Made in China 2025, the civil engineering industry has a clear trend towards intelligent manufacturing. In order to consolidate China's international voice and leadership, the development of the civil engineering industry must follow the trend and follow the national development plan.

This article introduces the development trend of prefabricated engineering structure, intelligent manufacturing, 3D printing technology and digitalization. At the same time, combined with the current domestic and foreign development environment of the civil engineering industry, it is concluded that the next generation of civil engineering will inevitably develop towards the assembly of structural forms, the mechanization of construction modes, the intelligent management of management methods, and the digital development of information management. These conclusions can provide a powerful reference for the national government to formulate future development strategic plans and enterprises to formulate future development plans.

\section{Acknowledgments}

This research was supported by research funds provided by National Natural Science Foundation of ChinaNational Project for Research and Development of Major Scientific Instruments (grant number 51727813).

\section{References}

1. Sun J(2019). Intelligent manufacturing improvement of SMT production line based on MES. North China Institute of Aerospace Engineering. 2019: 40-42.

2. Chen $\mathrm{KH}(2021)$. Accelerate the digital transformation of innovation and development. Strategic frontier technology. 2021-04-03.

3. Xie, JK; Gao, B; Cheng, $\operatorname{HM(2021).~Research~and~}$ Development of Civil Engineering Intelligent Structure System. Advances in civil engineering. 2021:01(28). DOI: 10.1155/2021/8814676.

4. Shrive, NG(2005). Intelligent structural health monitoring: a civil engineering perspective. IEEE International Conference on Systems Man and Cybernetics Conference Proceedings. 2005:19731977.

5. Wang XW(2021). 96 complete PPTs clearly explain the global intelligent manufacturing trend!. Frontline of Industrial Internet. 2021-04-04.
6. Gu MX(2021). Academician Xiao Xuwen: What is intelligent construction, why, what, and how?. China Construction News. 2021-04-06.

7. Edit(2021). There is no successor in the construction industry? Worry too much! The construction robot is on the road. Collected by China Curtain Wall Network. 2021-04-07.

8. Su LC(2020). Concrete 3D printed arch bridge[J]. China Highway,2020(5):63-65.

9. $\mathrm{Xu}$ WG et al(2021). Robot 3D printing concrete bookstore [N]. Gooood design network. 2021-03-30.

10. Na DD, Li Y(2021). Research on Policy Tools for Digital Transformation of my country's Manufacturing Industry[J]. Administrative Forum,2021,28(1):92-97. 